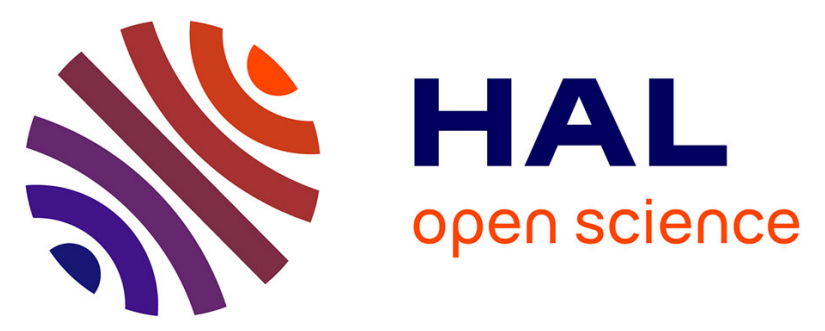

\title{
Hepatocyte growth factor activator inhibitor-1 has a complex subcellular itinerary
}

Sine Godiksen, Joanna Selzer-Plon, Esben D.K. Pedersen, Kathrine Abell, Hanne Borger Rasmussen, Roman Szabo, Thomas H Bugge, Lotte K. Vogel

\section{- To cite this version:}

Sine Godiksen, Joanna Selzer-Plon, Esben D.K. Pedersen, Kathrine Abell, Hanne Borger Rasmussen, et al.. Hepatocyte growth factor activator inhibitor-1 has a complex subcellular itinerary. Biochemical Journal, 2008, 413 (2), pp.251-259. 10.1042/BJ20071496 . hal-00478909

\section{HAL Id: hal-00478909 https://hal.science/hal-00478909}

Submitted on 30 Apr 2010

HAL is a multi-disciplinary open access archive for the deposit and dissemination of scientific research documents, whether they are published or not. The documents may come from teaching and research institutions in France or abroad, or from public or private research centers.
L'archive ouverte pluridisciplinaire HAL, est destinée au dépôt et à la diffusion de documents scientifiques de niveau recherche, publiés ou non, émanant des établissements d'enseignement et de recherche français ou étrangers, des laboratoires publics ou privés. 


\section{Hepatocyte Growth Factor Activator Inhibitor-1 has a Complex Subcellular Itinerary}

\section{Sine Godiksen ${ }^{*}$ Joanna Selzer-Plon ${ }^{*}$, Esben D.K. Pedersen ${ }^{*}$, Kathrine Abell, Hanne B. Rasmussen§, Roman Szabo", Thomas H. Buggeף and Lotte K. Vogel $^{* 1}$}

*Department of Cellular and Molecular Medicine, University of Copenhagen, The Panum Institute, Blegdamsvej 3, DK-2200 Copenhagen N, Denmark, ${ }^{\S}$ Department of Biomedical Sciences, University of Copenhagen, The Panum Institute, Blegdamsvej 3, DK-2200 Copenhagen N, Denmark, and Proteases and Tissue Remodeling Unit, National Institute of Dental and Craniofacial Research, National Institutes of Health, Bethesda, MD 20892, USA.

${ }^{1}$ To whom correspondence should be addressed (e-mail vogel@imbg.ku.dk)

Running head: Subcellular Itinerary of HAI-1

The abbreviations used are: MDCK, Madin-Darby canine kidney; HAI-1, hepatocyte growth factor activator inhibitor-1; HGF, hepatocyte growth factor. 
Hepatocyte growth factor activator inhibitor-1 (HAI-1) is a Kunitz-type transmembrane serine protease inhibitor that forms inhibitor complexes with the trypsin-like serine protease, matriptase. HAI-1 is essential for mouse placental development and embryo survival and together with matriptase it is a key regulator of carcinogenesis. HAI-1 is expressed in polarized epithelial cells, which have the plasma membrane divided by tight junctions into an apical and a basolateral domain. Here we show that HAI-1 at steady state is mainly located on the basolateral membrane of both Madin-Darby Canine Kidney cells and mammary gland epithelial cells. After biosynthesis HAI-1 is exocytosed mainly to the basolateral plasma membrane from where $15 \%$ of the HAI-1 molecules are proteolytically cleaved and released into the basolateral medium. The remaining membrane-associated HAI-1 is endocytosed and then recycles between the basolateral plasma membrane and endosomes for hours until it is trancytosed to the apical plasma membrane. Minor amounts of HAI-1 present at the apical plasma membrane are proteolytically cleaved and released into the apical medium. Full-length membrane-bound HAI-1 has a half life of $1.5 \mathrm{~h}$ and is eventually degraded in the lysosomes, whereas proteolytically released HAI-1 is more stable. HAI-1 is co-localized with its cognate protease, matriptase, at the basolateral plasma membrane. We suggest that HAI-1, in addition to its protease inhibitory function, plays a role in transporting matriptase as a matriptase-HAI-1 complex from the basolateral plama membrane to the apical plasma membrane, as matriptase is known to interact with prostasin, located at the apical plasma membrane.

Key words; HAI-1, endocytosis, transcytosis, lysosomal degradation, proteolytic release 


\section{INTRODUCTION}

It is becoming increasingly clear that extracellular proteases and protease inhibitors play an important role in cellular migration and differentiation during normal development. In most cases genetic ablation of the protease inhibitor has no effect, suggesting an extensive developmental redundancy. However, the protease inhibitor hepatocyte growth factor activator inhibitor -1 (HAI-1) has been shown to be essential during embryonic development, as HAI-1-deficient mouse embryos die during mid-gestation [1]. HAI-1 is an inhibitor of several serine proteases including matriptase. Matriptase-deficient mice die shortly after birth [2]. Mice deficient in both HAI-1 and matriptase develop to term and are born with the same phenotype as a matriptase-deficient mouse [3]. This shows that HAI-1 is an essential non-redundant inhibitor of matriptase during prenatal development. In addition, recent studies in zebrafish have shown that matriptase and HAI-1 regulate skin homeostasis and remodelling [4]. In this study it was shown that an insertion in the HAI-1 gene caused an accumulation of neutrophils in the fin which could be rescued by knock-down of matriptase, suggesting that HAI-1 and matriptase also play a role in regulating inflammation. The protease-protease inhibitor pair, matriptase and HAI-1, has also been shown to play an important role in carcinogenesis. Modest over-expression of matriptase in the skin of transgenic mice caused spontaneous squamous cell carcinoma, accompanied by dramatically potentiated carcinogeninduced tumour formation. Simultaneous over-expression of HAI-1, however, completely negated the oncogenic effects of matriptase over-expression [5].

HAI-1 is a Kunitz-type serine protease inhibitor and was first identified as an inhibitor of hepatocyte growth factor activator, a blood coagulation factor XII-like serine protease [6]. It has later been shown to also inhibit matriptase [7], prostasin [8] and hepsin [9]. Full-length HAI-1 is composed of 513 amino acids and consists of two well-defined extracellular Kunitz domains, KD1 (residues 246-306) and KD2 (residues 371-431), a LDLR (low density lipoprotein receptor-like domain) class A domain (residues 315-360), a transmembrane domain and a short C-terminal cytoplasmic domain [6]. HAI-1 is expressed in most epithelial cells including kidney, placenta, pancreas, prostate, intestine and lung $[6 ; 10]$.

Matriptase is a type II transmembrane serine protease that is expressed in many epithelial cells and some hematopoietic cells [11-13]. Matriptase activates the serine proteases, prostasin [14] and 
uPA [15;16], as well as non-protease substrates such as protease-activated receptor 2 [15] and HGF [16] via proteolytic cleavage.

Epithelial cells form a tight mono-layer of cells that line the internal surfaces of our organs and the external surfaces of our bodies. Many of these are specialized for absorption and secretion. The entire organization of the epithelium is polarized, which is most easily observed at the plasma membrane, as this is divided into an apical and a basolateral membrane. The plasma membrane is divided by tight junctions between neighbouring cells into two membrane domains; the apical membrane domain and the basolateral membrane domain [17]. The functions of the two membrane domains are distinct, and their lipid and protein composition strikingly different. The tight junctions prevent the mixing of outer-leaflet proteins and lipids between the two surfaces, and also acts as a selective barrier between adjacent cells to prevent large molecules from crossing the epithelial layer $[18 ; 19]$.

As described, the activity of matriptase is tightly regulated by its interaction with HAI-1. However, matriptase and HAI-1 are expressed in the same cells. In order to gain an understanding of the time and place for the molecular interaction between them it is necessary to map the intracellular itinerary of these molecules as well as their molecular interactions. In the present study we have investigated the subcellular itinerary of HAI-1 in the natural environment for these molecules - a polarized epithelial cell. Our results show that matriptase and HAI-1 are co-localized at the basolateral plasma membrane and that HAI-1 has a complex subcellular itinerary, including transcytosis from the basolateral to the apical plasma membrane.

\section{EXPERIMENTAL}

\section{Cell Culture and DNA Constructions}

MDCK cells were grown in minimal essential medium supplemented with $2 \mathrm{mM}$ L-glutamine, $10 \%$ fetal bovine serum, 100 units $/ \mathrm{ml}$ penicillin, and $100 \mu \mathrm{g} / \mathrm{ml}$ streptomycin (Gibco, USA) at $37^{\circ} \mathrm{C}$ in an atmosphere of $5 \% \mathrm{CO}_{2}$. Cells were transfected with the eukaryote expression plasmid pMH containing the cDNA encoding full-length murine HAI-1 or encoding the full-length murine matriptase (epithin) cDNA. Subconfluent MDCK cells were transfected by the calcium phosphate transfection procedure as described [20]. The transfected cells were selected using $0.65 \mathrm{mg} / \mathrm{ml} \mathrm{G} 418$, and stable clones were isolated using cloning cylinders. For most experiments, $10^{6}$ cells per well were seeded into $24-\mathrm{mm}$ Transwell chambers 
(Costar Europe Ltd., The Netherlands), allowing separate access to the apical and basolateral membrane. The medium was changed every 2 or 3 days. Filters were used for experiments 3-6 days after confluence as indicated by tightness of the filters. The tightness of filter-grown cells was assayed by filling the inner chamber to the brim and allowing it to equilibrate overnight.

\section{Immunofluorescence}

MDCK cells expressing HAI-1 grown on coverslips or on filters or mammary gland cryosections were fixed in $4 \%$ paraformaldehyde in PBS. Unspecific staining was blocked with PBS, $1 \mathrm{mM} \mathrm{MgCl} 2$ and $0.1 \mathrm{mM}$ $\mathrm{CaCl}_{2}\left(\mathrm{PBS}^{++}\right)$containing 3\% BSA for $20 \mathrm{~min}$ at room temperature. In some cases cells were immunostained before permeabilization in the following manner: cells were incubated with primary antibody diluted in $\mathrm{PBS}^{++} 3 \% \mathrm{BSA}$ (PBS/BSA) for $1 \mathrm{~h}$ at room temperature, rinsed 3 times with PBS/BSA followed by incubation with relevant Alexa Fluor conjugated secondary antibodies (Invitrogen, Denmark) (1:300) for 45 min at room temperature. Where indicated, cells were permeabilized with PBS/BSA $0.1 \%$ Triton X-100 for $20 \mathrm{~min}$. Labelling of intracellular antigens was performed as described for surface staining except $0.1 \%$ Triton-X 100 was included in all buffers. If indicated, sections were subsequently incubated with streptavidin-conjugated Alexa Fluor 594 (Invitrogen, Denmark) diluted 1:300 and finally mounted with DAPI vectashield hard set mounting medium (VWR, USA) and subjected to laser scanning confocal microscopy using the Leica TCS SP2 system.

Where indicated, cells were treated with $200 \mathrm{nM}$ bafilomycin (Sigma Aldrich, USA) for 24 hours before fixation. Primary antibodies employed were: goat anti-mouse HAI-1 antibody (cat. no: AF1141, R\&D systems, USA) diluted 1:8000, and rabbit anti-matriptase antibody (cat. no: IM1014, Calbiochem, Germany) diluted 1:1000.

\section{Immunoblotting}

$10 \%$ NU-PAGE gels were ûsed according to the instructions of the manufacturer and semidry blotted to Immobilon-P PVDF membranes (Millipore, USA). The blots were blocked with 2\% Tween-20 in PBS, probed with anti-HAI-1 antibody (1:1000), then probed with an appropriate secondary antibody. The signal was developed using an enhanced chemiluminescent substrate (ECL) reagent according to the protocol supplied by the manufacturer (Amersham Pharmacia Biotech., UK) and developed with a Fuji LAS1000camera (FujiFilm Sverige AB, Stockholm, Sweden).

\section{RT-PCR}


Total RNA was purified from MDCK cells as recommended by the manufacturers using E.Z.N.A. Total RNA Kit II (VWR, USA). RNA purification included a DNAse treatment. The cDNA synthesis was performed on approximately $150 \mathrm{ng}$ RNA per $20 \mu \mathrm{l}$ using High-Capacity cDNA Archive Kit (Applied Biosystems, USA). Quantitative Power SYBR Green PCR master mix (Applied Biosystems, USA) was used together with $900 \mathrm{nM}$ of each primer. Primers were designed using Primer Express v3.0 Software and placed within different exons. Quantitative RT-PCR was performed on ABI 7300 sequence detection system (Applied Biosystems, USA). Primers were obtained from TAC, Copenhagen. Canine matriptase: primers were matriptase $\mathrm{F}$, 5'-TGGCTTGCCTCCTGATGTG-3'; matriptase R, 5'TGATCCTCAGGTAGCCATTGAA-3'. Canine HAI-1: primers were HAI-1 F, 5'TTtGagGagGagCAGCAGTGT-3'; HAI-1 R, 5'- GCCGCAGGCCGAAAAC-3'. Canine $\beta$-actin: primers were $\beta$-actin $\mathrm{F}, \quad 5^{\prime}$-CGACAGGATGCAGAAGGAAATC-3'; $\beta$-actin $\quad \mathrm{R}, \quad 5^{\prime}$ CGTTCCGGAGGAGCAATG-3'. Negative controls (where the RNA was not converted into cDNA) and positive controls were included.

\section{Metabolic Labelling, Biotinylation, Immunoprecipitations and Streptavidin precipitations}

Metabolic labelling was performed on tight filter grown cells using $0.25 \mathrm{mCi}$ of [35S] methionine in $1 \mathrm{ml}$ per well as described [20]. Biotinylation and stripping of biotin using glutathione was performed essentially as described in [21;22]. Cells were washed three time in PBS and biotinylated with $1 \mathrm{mg} / \mathrm{ml}$ sulfo-NHS-SSbiotin in the same buffer at $4^{\circ} \mathrm{C}$ for $30 \mathrm{~min}$. The reaction was quenched by washing the cells three times in PBS, by a 5-min incubation with $50 \mathrm{mM}$ glycine in PBS, and by another 3 washes with PBS. The cells were then incubated in media (described above) for the indicated time at either $4{ }^{\circ} \mathrm{C}$ or $37^{\circ} \mathrm{C}$. If indicated, cell surface biotin was stripped with two 20-min incubations with $50 \mathrm{mM}$ reduced glutathione, $75 \mathrm{mM} \mathrm{NaCl}, 75$ $\mathrm{mM} \mathrm{NaOH}, 1 \mathrm{mM}$ EDTA with $1 \%$ bovine serum albumin. Cells were subsequently rinsed twice with PBS and incubated for $5 \mathrm{~min}$ with $5 \mathrm{mg} / \mathrm{ml}$ iodoacetamide in PBS to quench any residual glutathione. After two additional rinses with PBS cells were either extracted for western blotting or prepared for immunoprecipitation. For immunoprecipitation, the cells were lysed in PBS containing 1\% Triton X-100, 5 $\mathrm{mM}$ EDTA, and $0.5 \%$ deoxycholate for $30 \mathrm{~min}$ at $4{ }^{\circ} \mathrm{C}$ and the apical and basolateral media were collected. The extracts were centrifuged 5,000 $\times \mathrm{g}$ for $2 \mathrm{~min}$, and the supernatant was recovered and incubated for 60 min with $100 \mu \mathrm{l}$ of a $50 \%$ protein A-sepharose slurry and incubated $2 \mathrm{~h}$ at $4{ }^{\circ} \mathrm{C}$. The supernatant was recovered after centrifugation 5,000 x g for 2 min and $100 \mu \mathrm{HAI}-1$ antibody (diluted 1:100) and $20 \mu \mathrm{l} 50 \%$ protein A sepharose slurry were added. The sample was rotated end-over-end for 2.5 hours at $4^{\circ} \mathrm{C}$. The immunoprecipitates were washed five times in $50 \mathrm{mM}$ Tris-HCl, $1.0 \% \mathrm{NP}-40,500 \mathrm{mM} \mathrm{NaCl}, \mathrm{pH} 8.0$ ). The immunoprecipitates were in some cases analyzed by electrophoresis on 10\% SDS-PAGE gels. The gels were dried, exposed to x-ray films, and processed for densitometry or analyzed on a phosphorimager (Molecular 
Dynamics PhosphorImager SITM, USA). Alternatively, for streptavidin precipitation the immunoprecipitate was boiled in $80 \mu \mathrm{l}$ of SDS-PAGE sample buffer without dithiothreitol and diluted in $1 \mathrm{ml}$ of $25 \mathrm{mM}$ Tris$\mathrm{HCl}, \mathrm{pH}$ 7.8, $250 \mathrm{mM} \mathrm{NaCl}, 5 \mathrm{mM}$ EDTA, 1\% Triton X-100, 1\% BSA, and 10\% fetal bovine serum and spun $3000 \times \mathrm{g}$ for $5 \mathrm{~min}$. The supernatant was then incubated with streptavidin agarose $(50 \mu \mathrm{l}$ of a $50 \%$ slurry) at $4{ }^{\circ} \mathrm{C}$ overnight. The streptavidin beads were washed four times with $25 \mathrm{mM}$ Tris-HCl, $\mathrm{pH} 7.8,500$ $\mathrm{mM} \mathrm{NaCl}$, and $0.5 \%$ Triton X-100 and then three times in $10 \mathrm{mM}$ Tris- $\mathrm{HCl}, \mathrm{pH} 7.8$, and $150 \mathrm{mM} \mathrm{NaCl}$. The streptavidin precipitate was analyzed on $10 \%$ SDS-PAGE gels. The gels were dried and analyzed on a phosphorimager.

\section{RESULTS}

\section{HAI-1 can be recombinantly expressed in MDCK cells}

The cDNA coding for the full-length wild type murine HAI-1 was incorporated into the eukaryotic expression vector $\mathrm{pMH}$ and transfected into MDCK cells. Twenty-four G418 resistant clones were isolated and the majority of the clones showed HAI-1 expression as tested by immunocytochemistry (data not shown). All clones showed a similar pattern of expression characteristic of basolaterally expressed proteins e.g. along the cell periphery. One clone (clone 21) was selected for further investigation based on intensity of the immunocytochemistry reactions. No immunostaining could be detected in non-transfected cells or in transfected cells when the primary antibody was omitted. A cell extract of clone 21 was analyzed by western blotting using conventional SDS-PAGE gels and showed a HAI-1 immunoreactive band of $52 \mathrm{kDa}$ under non-reducing conditions, whereas no immunoreactive band could be detected in non-transfected MDCK cells (Fig. 1). Bands of equal intensity could be identified after stripping of the blots and reprobing with an antibody against the transferrin receptor indicating that equal amounts of sample were loaded in the two wells. Our findings correspond well with the molecular weight of HAI-1 found in other studies (55-66 kDa) $[23 ; 24]$.

\section{MDCK cells have an endogenous expression of HAI-1 and matriptase.}

In order to investigate whether MDCK cells have an endogenous expression of the canine matriptase and HAI-1 mRNAs we used quantitative real time RT-PCR and normalized to the expression of canine $\beta$-actin mRNA. Total RNA was extracted from MDCK cells and was, after cDNA synthesis, used as template in a quantitative real-time PCR reaction. The mRNA level of 
matriptase and HAI-1 relative to the expression of canine $\beta$-actin was 0.11 and 0.06 , respectively. No signal could be detected when reverse transcriptase was omitted. Analysis of the melting curves and analysis of the products on agarose gels showed that there was only a single PCR product of the expected size. The detection of significant amounts of the canine mRNAs suggests that MDCK cells have an endogenous expression of both HAI-1 and matriptase and that this cell line is a relevant model for studies of the intracellular transport of these proteins.

\section{At steady state the majority of HAI-1 is located at the basolateral plasma membrane in vitro in MDCK cells and in vivo in murine mammary glands}

In order to evaluate the steady state distribution of exogenously expressed HAI-1 in MDCK cells we analyzed the distribution of HAI-1 between intracellular and extracellular compartments of the cell. Clone 21 cells were grown on coverslips, fixed and thereafter surface HAI-1 (termed HAI$1_{\text {surface }}$ hereafter) was visualized by immunofluorescence in the absence of detergent (Fig. 2. panel a and d). Next, cells were permeabilized and HAI-1 detected again using the same primary antibody but a different secondary antibody to indicate the localization of both intracellular and extracellular HAI-1 (termed HAI- $1_{\text {total }}$ hereafter) (Fig. 2 panel b and e). Confocal microscopy of cells stained in this manner revealed that the majority of $\mathrm{HAI}-1_{\text {total }}$ co-localizes with HAI- $1_{\text {surface }}$ and only a minor fraction of $\mathrm{HAI}-1_{\text {total }}$ is not co-localized with HAI- $1_{\text {surface. The intracellular material represents }}$ newly synthesized molecules on their way to the plasma membrane, but may also include material that after endocytosis is undergoing transport to other cellular destinations.

To evaluate the distribution of HAI-1 between the apical and the basolateral plasma membrane, clone 21 cells were grown on filters until confluence, biotinylated on either the apical (Fig. 2. panel g-i) or the basolateral (Fig. 2. panel j-1) plasma membrane and thereafter processed for immunofluorescence. The cells were labelled for surface HAI-1 (Fig. 2 panel h and k), whereas biotinylated proteins were visualised using Alexa Fluor 594 labelled streptavidin (Fig. 2 panel $g$ and j). We found that the vast majority of HAI-1 co-localized with proteins biotinylated from the basolateral side but occasionally faint staining for HAI-I in scattered dots could be detected on the apical plasma membrane. In order to verify that the basolateral localization of HAI-1 in MDCK cells reflects a physiological situation we next investigated the subcellular localization of HAI-1 in mammary epithelial cells. Mammary epithelial tissue was taken from a mouse at the $10^{\text {th }}$ day of lactation. Paraformaldehyde fixed cryosections were labelled with anti-HAI-1 antibodies in the presence of detergents and analyzed by confocal microscopy. A clear basolateral localization of 
HAI-1 was observed (Fig. 2 panel m). Similar results were obtained with mouse mammary glands at the time of birth and at the $2^{\text {nd }}$ day of involution (data not shown).

HAI-1 is a physiologically important inhibitor of matriptase and the two proteins have been purified as a complex, showing that they interact directly [7]. To investigate in which subcellular compartments matriptase and HAI-1 co-localize, clone 21 cells were transiently transfected with an expression vector coding for full-length murine matriptase and seeded on coverslips. The transfected cells were double-labelled with antibodies directed against HAI-1 (Fig. 2 panel n) and matriptase (Fig. 2 panel o) and the localization of the two proteins was analyzed by confocal microscopy. The matriptase antibody did not detect the canine matriptase endogenously expressed in MDCK cells as no labelling could be detected in non-transfected clone 21 cells (data not shown). However, we could detect clone 21 cells transiently expressing matriptase co-localizing with HAI-1 on the basolateral plasma membrane (Fig. 2 panel p).

\section{HAI-1 is exocytosed primarily to the basolateral plasma membrane}

To study the appearance of newly synthesized proteins on the two cell surface domains, tight filter grown cells were pulse labelled with [35S]methionine for $10 \mathrm{~min}$, and after various chase times the plasma membrane proteins present on either the apical or basolateral domains were biotinylated using a membrane non-permeant biotinylation reagent. Biotinylated HAI-1 was purified by immunoprecipitation using protein A-sepharose, released from the beads by boiling and reprecipitated with streptavidin-agarose. The resulting purified antigens were analyzed on NuPAGE gels, and quantified on a phosphorimager. The analysis showed that newly synthesised HAI-1 appears as a clear transient pool on the basolateral plasma membrane, peaking at 1 hour of chase (Fig. 3). A smaller transient pool can be seen on the apical plasma membrane, displaying a broad peak at 0.5-2 hour of chase. These results show that the majority of HAI-1 is initially exocytosed to the basolateral plasma membrane. After short chase times minor amounts of HAI-1 appear at the apical and the basolateral plasma membrane with the same kinetics. It can thus not be excluded that minor amounts of HAI-1 are transported directly from the Golgi apparatus to the apical plasma membrane.

\section{A fraction of HAI-1 is secreted to the basolateral side of MDCK cells whereas the majority remains cell-associated}


To investigate whether the HAI-1 ectodomain is released to the apical or basolateral sides, clone 21 cells were grown to confluence on transwells, biosynthetically labelled with [35S] methionine for 10 minutes and chased for the times indicated (Fig. 4). The apical media, the basolateral media and the cell extracts were collected at various time points. HAI-1 was immunoprecipitated and analyzed on NuPAGE gels and quantitated using a phosphorimager. A band of $52 \mathrm{kDa}$ presumably representing full-length membrane-bound HAI-1 could be seen in the cell extracts after short chase times. This membrane-bound form has a relatively short half life of 1.5 hours. At later time points immunoreactive bands, which appear to have a precursor product relationship with the $52 \mathrm{kDa}$ band, appear in the cell extract suggesting that the $52 \mathrm{kDa}$ band is successively degraded. After 2 hours of chase, about $15 \%$ of the HAI-1 immunoreactive species can be detected in the basolateral media and $2 \%$ in the apical media. These fractions are relatively stable and are still present after 5 hours of chase. These results show that in MDCK cells minor amounts of HAI-1 are proteolytically released into the media.

\section{Plasma membrane-associated HAI-1 is rapidly endocytosed}

In order to investigate whether HAI-1 on the plasma membrane is endocytosed, clone 21 cells were grown on plastic to subconfluence, and proteins on the plama membrane were biotinylated using a cleavable biotinylation reagent, s-NHS-SS-biotin. The cells were then allowed to endocytose for the time indicated at either $4{ }^{\circ} \mathrm{C}$ or $37{ }^{\circ} \mathrm{C}$. Thereafter, surface-exposed biotin was stripped using a membrane non-permeant reducing agent, glutathione. The cells were extracted and streptavidin precipitated, and thereafter analyzed by western blotting using a HAI-1 antibody. The western blot was quantitated using image gauge. When the cells were biotinylated at $4{ }^{\circ} \mathrm{C}$ and immediately stripped, only a minor background of biotinylated HAI-1 could be detected, showing that the stripping procedure is efficient (Fig. 5). Significantly higher signals could be detected when cells were allowed to endocytose at $37^{\circ} \mathrm{C}$ for 5,10 or 15 minutes before stripping, showing that some HAI-1 molecules have now acquired protection from the non-membrane-permeant reduction procedure. Maximal signal was detected when the cells were allowed to endocytose for $10 \mathrm{~min}$. After 15 min of chase the signal was reduced, possibly due to recycling or degradation of HAI-1. The maximal signals after 10 min was approximately $75 \%$ of the total surface biotinylated HAI- 1 (Fig. 5). These results show that HAI-1 at the plasma membrane is rapidly endocytosed.

\section{Partial transcytosis of HAI-1 from the basolateral to the apical plasma membrane}


To account for the very large concentration of HAI-1 in complex with matriptase that has been purified from milk [7] it may be suggested that the basolateral pool of HAI-1 is transcytosed from the basolateral to the apical plasma membrane and released. To assess directly whether newly synthesized HAI-1 that appears on the basolateral membrane is routed to the apical plasma membrane, we used the following protocol: Tight clone 21 cells grown on filters were pulse labelled with $\left[{ }^{35} \mathrm{~S}\right]$ methionine for $90 \mathrm{~min}$ to ensure maximal labelling of HAI-1 molecules at the basolateral plasma membrane. The cells were then biotinylated on the basolateral surface with the cleavable reagent s-NHS-SS-Biotin at $4{ }^{\circ} \mathrm{C}$, followed by a second chase for 0 or 4 hours in order to allow transcytosis to occur. At the indicated times, the cells were either reduced twice with glutathione from the apical side or from the basolateral side, or reduction was omitted. This experiment demonstrated that HAI-1, biotinylated from the basolateral side after 4 hours of chase at $37{ }^{\circ} \mathrm{C}$, can be reduced from the apical side, indicating that a significant fraction of the HAI-1 molecules biotinylated on the basolateral plasma membrane is transcytosed to the apical plasma membrane (Fig. 6). In addition, a significant fraction of HAI-1 molecules could be reduced from the basolateral side after $4 \mathrm{~h}$ of chase. This suggests that HAI-1 recycles between endosomes and the basolateral plasma membrane as the endocytosis rate is substantial (see Fig. 5). A control experiment showed that without a second chase the biotin could be reduced from the basolateral side, but not from the apical side.

\section{Membrane-bound HAI-1 is eventually degraded in the lysosomes.}

To investigate whether HAI-1 is degraded in lysosomes we applied bafilomycin. Bafilomycin is a microbial toxin that reduces delivery of internalised proteins in multi-vesicular endosomes to the late endosomes/lysosomes [25]. Cells were grown on coverslips and pre-treated with $200 \mathrm{mM}$ bafilomycin for 24 hours or bafilomycin-treatment was omitted. Cells were then fixed and stained to visualise $\mathrm{HAI}-1_{\text {surface }}$ and $\mathrm{HAI}-1_{\text {total }}$ as described previously. Confocal microscopy of the bafilomycin-treated cells showed that the major part of HAI- $1_{\text {total }}$ is co-localized with HAI- $1_{\text {surface }}$ (Fig. 7). However, a substantial fraction of HAI- $1_{\text {total }}$ does not co-localize with HAI- $1_{\text {surface }}$ and represents intracellular HAI-1. This intracellular HAI-1 is not present in non-treated cells and demonstrates that HAI-1 is indeed accumulating in an intracellular compartment upon bafilomycin treatment, indicating that membrane bound HAI-1 is eventually degraded in the lysosomes. We also tested whether HAI-1 co-localized with the lysosomal enzyme cathepsin D. However, no co- 
localization could be detected (data not shown) probably due a low steady state concentration of HAI-1 in the lysosomes.

\section{DISCUSSION}

In the present study we have mapped the subcellular itinerary of recombinantly expressed murine HAI-1 in the canine MDCK cell line. HAI-1 is expressed in vivo in many types of polarized epithelial cells and is near ubiquitously co-expressed with the protease matriptase $[3 ; 10 ; 26]$. We have demonstrated that MDCK cells have an endogenous expression of both canine HAI-1 and canine matriptase, showing that MDCK cells are a relevant cell line for the study of the subcellular itinerary of these proteins. In the present study we have recombinantly expressed both murine HAI1 and murine matriptase and studied their subcellular localization using antibodies not recognizing the endogenously expressed canine proteins, thereby proving the identity of the studied proteins.

At steady state, HAI-1 was found mainly on the basolateral plasma membrane in MDCK cells. This may seem contradictory to the fact that HAI-1 in complex with matriptase has been purified from milk [7]. We therefore investigated the subcellular localization of HAI-1 in mouse mammary gland epithelial cells during lactation and found that HAI-1 could be detected on the basolateral plasma membrane, again suggesting that the MDCK cells are a physiologically relevant model for studies of HAI-1 trafficking in polarized epithelial cells in vivo. Previous studies have shown that HAI-1 is located mainly on the basolateral plasma membrane in kidney cells [27] and a range of other polarized epithelial cells [6;10;27].

The major part of the newly synthesised HAI-1 is exocytosed to the basolateral plasma membrane (Fig. 8, arrow A) from which it is rapidly endocytosed (Fig. 8, arrow C). From the basolateral plasma membrane there was a rapid endocytosis of approximately $75 \%$ of the total cell surface HAI-1 every 10 minutes. However, the transcytosis studies showed that after 4 hours of chase $\sim 30 \%$ of HAI-1 was still reducible from the basolateral side. This suggests that HAI-1 recycles between the basolateral plasma membrane and endosomes for hours (Fig. 8, arrow D), which gives an explanation for the large pool of HAI-1 present at the basolateral membrane despite the rapid endocytosis rate. There are many examples of proteins recycling in a similar manner [28].

About $15 \%$ of HAI-1 in MDCK cells is proteolytically released into the basolateral media. This fraction is composed of a $45 \mathrm{kDa}$ and a $40 \mathrm{kDa}$ fragment. Proteolytic release of HAI-1 fragments has previously been reported from non-polarized cells [8;27;29]. There is at present no 
data to indicate whether a similar release of HAI-1 from the basolateral plasma membrane takes place in vivo. It is noteworthy that only a fraction of the HAI-1 molecules present on the basolateral membrane seems to be released. The degree of proteolytic release of membrane-bound proteins has previously been shown to depend on the degree of glycosylation. This is true for both $\mathrm{N}$ glycosylation [30] and O-glycosylation [31;32]. Human HAI-1 has been reported to contain three $\mathrm{N}$-glycosylation sites [33]. Murine HAI-1 contains only one potential N-glycosylation site and one potential O-glycosylation consensus site at threonine 438 of the murine HAI- 1 , as analyzed by the NetOGlyc 3.1 server [34]. To our knowledge there is no data to about whether release of HAI-1 is dependent of glycosylation.

Despite a low steady state pool of HAI-1 at the apical plasma membrane, our data suggests that HAI-1 does pass through this subcellular compartment during its cellular itinerary, made evident by the fact that significant amounts of HAI-1 are transcytosed from the basolateral to the apical plasma membrane (Fig. 8, arrow $\mathrm{C}$ and $\mathrm{E}$ ). However, it is also possible that minor amounts of HAI-1 are exocytosed directly to the apical plasma membrane (Fig 8, arrow B), not bypassing the basolateral plasma membrane.

Tight filter grown MDCK cells are not absolutely tight, but soluble protein leaks through the filter in the order of 5\% during 6 hours [35]. Our results showed that only a minor part of the HAI-1 was proteolytically released. The proteolytically released HAI-1 is distributed between the apical and the basolateral media as $11 \%$ and $89 \%$ respectively. Thus, the fraction of the soluble HAI-1 released into the apical media most likely represents molecules proteolytically released from the apical membrane as opposed to non-specific leakage though the monolayer of cells. Milk has been reported to be a rich source of HAI-1 in complex with matriptase [7]. To account for the large amount found in milk it is possible that the apical plasma membrane of mammary epithelial cells harbours proteases that release a larger fraction of the HAI-1 molecules or alternatively that the biosynthesis is so large that even a release comprising a tenth of the biosynthesis is enough to generate the high concentration of proteolytically released HAI-1 found in milk.

In the present study we demonstrate that HAI-1 accumulates intracellularly upon treatment with bafilomycin, an inhibitor of transport to the lysosomes [36], suggesting that membrane-bound HAI-1 is degraded in the lysosomes. We were unable to show co-localization of HAI-1 with the lysosomal protease cathepsin D, but this may merely reflect that the steady state level of HAI-1 in the lysosomes is low due to a rapid turnover. We have not determined from which cellular compartment HAI-1 is directed to the lysosomes, but it is most likely that HAI-1 from the apical 
plasma membrane is directed to the lysosomes (Fig. 8, arrow F), as this would account for the low steady state level of HAI-1 on the apical plasma membrane.

In addition to a role in matriptase inhibition, HAI-1 is proposed to play a role in the activation and trafficking of matriptase [37;38]. Thus, in the absence of HAI-1, matriptase is found to accumulate in the Golgi apparatus [39]. Matriptase activates prostasin via a proteolytic cleavage and they probably constitute the first two members of a proteolytic cascade regulating terminal differentiation [40]. Prostasin is located on the apical plasma membrane [41], whereas matriptase is located on the basolateral membrane [42]. This leaves a spatial gap for the activation of prostasin by matriptase and potentially gives HAI-1 an important role in mediating the transport of matriptase from the basolateral membrane to the apical membrane via complex formation from where matriptase would be able to proteolytically activate prostasin. The MDCK cells recombinantly expressing HAI-1 and/or matriptase represent a model where it would be possible to obtain a better understanding of the subcellular sites of interaction between HAI-1 and matriptase and between matriptase and prostasin, which could give a better understanding of their role under normal physiological conditions as well as under pathological conditions, such as cancer. 


\section{Acknowledgements}

This work was supported by the Danish Medical Research Council (grant no 22-04-0467), The Danish Cancer Association, The Illum Foundation, The Etatsråd Georg Bestle and Wife's Foundation, The Aase and Ejnar Danielsens Foundation, the Danish Cancer Research Foundation, The Grosser Sven Hansen and wife Ina Hansens Foundation, Else and Mogens Wedell-Wedellborgs Foundation, Agnes and Poul Friis Foundation, The Family Hede Nielsens Foundation, Doctor Sofus Carl Emil Friis and wife Olga Doris Friis' foundation, The Harboe Foundation, The Augustinus Foundation, Aage and Johanne Louis Hansen Foundation, The Brothers Hartmanns Foundation, The Erland Richard Frederiksen and Wife Foundation , The A.P. Møller Foundation for the Advancement of Medical Science and the Lundbeck Foundation. 


\section{Reference List}

1 Tanaka, H., Nagaike, K., Takeda, N., Itoh, H., Kohama, K., Fukushima, T., Miyata, S., Uchiyama, S., Uchinokura, S., Shimomura, T., Miyazawa, K., Kitamura, N., Yamada, G., and Kataoka, H. (2005) Hepatocyte growth factor activator inhibitor type 1 (HAI-1) is required for branching morphogenesis in the chorioallantoic placenta. Molecular and Cellular Biology 25, $5687-5698$

2 List, K., Haudenschild, C. C., Szabo, R., Chen, W., Wahl, S. M., Swaim, W., Engelholm, L. H., Behrendt, N., and Bugge, T. H. (2002) Matriptase/MT-SP1 is required for postnatal survival, epidermal barrier function, hair follicle development, and thymic homeostasis. Oncogene 21, 3765-3779

3 Szabo, R., Molinolo, A., List, K., and Bugge, T. H. (2007) Matriptase inhibition by hepatocyte growth factor activator inhibitor-1 is essential for placental development. Oncogene 26, 15461556

4 Carney, T. J., von der Hardt, S., Sonntag, C., Amsterdam, A., Topczewski, J., Hopkins, N., and Hammerschmidt, M. (2006) Inactivation of serine protease Matriptase la by its inhibitor Hail is required for epithelial integrity of the zebrafish epidermis. Development 134, 34613471

5 List, K., Szabo, R., Molinolo, A., Sriuranpong, V., Redeye, V., Murdock, T., Burke, B., Nielsen, B. S., Gutkind, S. J., and Bugge, T. H. (2005) Deregulated matriptase causes rasindependent multistage carcinogenesis and promotes ras-mediated malignant transformation. Genes \& Development 19, 1934-1950

6 Shimomura, T., Denda, K., Kitamura, A., Kawaguchi, T., Kito, M., Kondo, J., Kagaya, S., Qin, L., Takata, H., Miyazawa, K., and Kitamura, N. (1997) Hepatocyte growth factor activator inhibitor, a novel Kunitz-type serine protease inhibitor. J.Biol.Chem. 272, 6370-6376

7 Lin, C. Y., Anders, J., Johnson, M., and Dickson, R. B. (1999) Purification and characterization of a complex containing matriptase and a Kunitz-type serine protease inhibitor from human milk. J.Biol.Chem. 274, 18237-18242

8 Fan, B., Wu, T. D., Li, W., and Kirchhofer, D. (2005) Identification of hepatocyte growth factor activator inhibitor-1B as a potential physiological inhibitor of prostasin. J.Biol.Chem.

9 Herter, S., Piper, D. E., Aaron, W., Gabriele, T., Cutler, G., Cao, P., Bhattt, A. S., Choe, Y., Craik, C. S., Walker, N., Meininger, D., Hoey, T., and Austin, R. J. (2005) Hepatocyte growth factor is a preferred in vitro substrate for human hepsin, a membrane-anchored serine protease implicated in prostate and ovarian cancers. Biochemical Journal 390, 125-136

10 Oberst, M., Anders, J., Xie, B., Singh, B., Ossandon, M., Johnson, M., Dickson, R. B., and Lin, C. Y. (2001) Matriptase and HAI-1 are expressed by normal and malignant epithelial cells in vitro and in vivo. Am.J.Pathol. 158, 1301-1311 
11 Oberst, M. D., Singh, B., Ozdemirli, M., Dickson, R. B., Johnson, M. D., and Lin, C. Y. (2003) Characterization of matriptase expression in normal human tissues. J.Histochem.Cytochem. 51, 1017-1025

12 List, K., Szabo, R., Molinolo, A., Nielsen, B. S., and Bugge, T. H. (2006) Delineation of matriptase protein expression by enzymatic gene trapping suggests diverging roles in barrier function, hair formation, and squamous cell carcinogenesis. American Journal of Pathology 168, $1513-1525$

13 Kilpatrick, L. M., Harris, R. L., Owen, K. A., Bass, R., Ghorayeb, C., Bar-Or, A., and Ellis, V. (2006) Initiation of plasminogen activation on the surface of monocytes expressing the type II transmembrane serine protease matriptase. Blood 108, 2616-2623

14 Netzel-Arnett, S., Currie, B. M., Szabo, R., Lin, C. Y., Chen, L. M., Chai, K. X., Antalis, T. M., Bugge, T. H., and List, K. (2006) Evidence for a matriptase-prostasin proteolytic cascade regulating terminal epidermal differentiation. J.Biol.Chem. 281,32941-32945

15 Takeuchi, T., Harris, J. L., Huang, W., Yan, K. W., Coughlin, S. R., and Craik, C. S. (2000) Cellular localization of membrane-type serine protease 1 and identification of proteaseactivated receptor- 2 and single-chain urokinase-type plasminogen activator as substrates. J.Biol.Chem. 275, 26333-26342

16 Lee, S. L., Dickson, R. B., and Lin, C. Y. (2000) Activation of hepatocyte growth factor and urokinase/plasminogen activator by matriptase, an epithelial membrane serine protease. Journal of Biological Chemistry 275, 36720-36725

17 Mostov, K. E. (2003) Epithelial polarity and morphogenesis. Methods 30, 189-190

18 Mostov, K., Su, T., and ter Beest, M. (2003) Polarized epithelial membrane traffic: conservation and plasticity. Nat.Cell Biol. 5, 287-293

19 Mostov, K. and Zegers, M. (2003) Cell biology: Just mix and patch. Nature 422, 267-268

20 Vogel, L. K., Sahkri, S., Sjostrom, H., Noren, O., and Spiess, M. (2002) Secretion of antithrombin is converted from nonpolarized to apical by exchanging its amino terminus for that of apically secreted family members. J.Biol.Chem. 277, 13883-13888

21 Pagano, A. and Spiess, M. (2005) Reconstitution of Rab4-dependent vesicle formation in vitro. Methods in Enzymology 403, 81-92

22 Pagano, A., Crottet, P., Prescianotto-Baschong, C., and Spiess, M. (2004) In vitro formation of recycling vesicles from endosomes requires adaptor protein-1/clathrin and is regulated by Rab4 and the connector rabaptin-5. Molecular Biology of the Cell 15, 4990-5000

23 Lee, M. S., Tseng, I. C., Wang, Y., Kiyomiya, K. I., Johnson, M. D., Dickson, R. B., and Lin, C. Y. (2007) Autoactivation of matriptase in vitro: requirement for biomembrane and LDL receptor domain. Am.J.Physiol Cell Physiol 
24 Denda, K., Shimomura, T., Kawaguchi, T., Miyazawa, K., and Kitamura, N. (2002) Functional characterization of Kunitz domains in hepatocyte growth factor activator inhibitor type 1. J.Biol.Chem. 277, 14053-14059

25 vanDeurs, B., Holm, P. K., and Sandvig, K. (1996) Inhibition of the vacuolar H+-ATPase with bafilomycin reduces delivery of internalized molecules from mature multivesicular endosomes to lysosomes in HEp-2 cells. European Journal of Cell Biology 69, 343-350

26 Oberst, M. D., Johnson, M. D., Dickson, R. B., Lin, C. Y., Singh, B., Stewart, M., Williams, A., al Nafussi, A., Smyth, J. F., Gabra, H., and Sellar, G. C. (2002) Expression of the serine protease matriptase and its inhibitor HAI-1 in epithelial ovarian cancer: correlation with clinical outcome and tumor clinicopathological parameters. Clin.Cancer Res. 8, 1101-1107

27 Kataoka, H., Suganuma, T., Shimomura, T., Itoh, H., Kitamura, N., Nabeshima, K., and Koono, M. (1999) Distribution of hepatocyte growth factor activator inhibitor type 1 (HAI-1) in human tissues. Cellular surface localization of HAI-1 in simple columnar epithelium and its modulated expression in injured and regenerative tissues. J.Histochem.Cytochem. 47, 673-682

28 Maxfield, F. R. and Mcgraw, T. E. (2004) Endocytic recycling, Nature Reviews Molecular Cell Biology 5, 121-132

29 Denda, K., Shimomura, T., Kawaguchi, T., Miyazawa, K, and Kitamura, N. (2002) Functional characterization of Kunitz domains in hepatocyte growth factor activator inhibitor type 1. J.Biol.Chem. 277, 14053-14059

30 Parry, S., Hanisch, F. G., Leir, S. H., Sutton-Smith, M., Morris, H. R., Dell, A., and Harris, A. (2006) N-Glycosylation of the MUC1 mucin in epithelial cells and secretions. Glycobiology 16, 623-634

31 Kato, K., Jeanneau, C., Tarp, M. A., Benet-Pages, A., Lorenz-Depiereux, B., Bennett, E. P., Mandel, U., Strom, T. M., and Clausen, H. (2006) Polypeptide GalNAc-transferase T3 and familial tumoral calcinosis. Secretion of fibroblast growth factor 23 requires O-glycosylation. J.Biol.Chem. 281, 18370-18377

32 Leuenberger, B., Hahn, D., Pischitzis, A., Hansen, M. K., and Sterchi, E. E. (2003) Human meprin beta: O-linked glycans in the intervening region of the type I membrane protein protect the C-terminal region from proteolytic cleavage and diminish its secretion. Biochem.J. 369, 659-665

33 Shimomura, T., Denda, K., Kawaguchi, T., Matsumoto, K., Miyazawa, K., and Kitamura, N. (1999) Multiple sites of proteolytic cleavage to release soluble forms of hepatocyte growth factor activator inhibitor type 1 from a transmembrane form. J.Biochem.(Tokyo) 126, 821-828

34 Julenius, K., Molgaard, A., Gupta, R., and Brunak, S. (2005) Prediction, conservation analysis, and structural characterization of mammalian mucin-type O-glycosylation sites. Glycobiology 15, 153-164

35 Vogel, L. K., Suske, G., Beato, M., Noren, O., and Sjostrom, H. (1993) Uteroglobin, an apically secreted protein of the uterine epithelium, is secreted non-polarized form MDCK cells and mainly basolaterally from Caco-2 cells. FEBS Lett. 330, 293-296 
36 Lerdrup, M., Hommelgaard, A. M., Grandal, M., and van Deurs, B. (2006) Geldanamycin stimulates internalization of ErbB2 in a proteasome-dependent way. J.Cell Sci. 119, 85-95

37 Oberst, M. D., Williams, C. A., Dickson, R. B., Johnson, M. D., and Lin, C. Y. (2003) The activation of matriptase requires its noncatalytic domains, serine protease domain, and its cognate inhibitor. Journal of Biological Chemistry 278, 26773-26779

38 Oberst, M. D., Chen, L. Y., Kiyomiya, K., Williams, C. A., Lee, M. S., Johnson, M. D., Dickson, R. B., and Lin, C. Y. (2005) HAI-1 regulates activation and expression of matriptase, a membrane-bound serine protease. Am.J.Physiol Cell Physiol 289, C462-C470

39 Oberst, M. D., Chen, L. Y., Kiyomiya, K., Williams, C. A., Lee, M. S., Johnson, M. D., Dickson, R. B., and Lin, C. Y. (2005) HAI-1 regulates activation and expression of matriptase, a membrane-bound serine protease. Am.J.Physiol Cell Physiol 289, C462-C470

40 Netzel-Arnett, S., Currie, B. M., Szabo, R., Lin, C. Y., Chen, L. M., Chai, K. X., Antalis, T. M., Bugge, T. H., and List, K. (2006) Evidence for a matriptase-prostasin proteolytic cascade regulating terminal epidermal differentiation. Journal of Biological Chemistry 281, 3294132945

41 Verghese, G. M., Gutknecht, M. F., and Caughey, G. H. (2006) Prostasin regulates epithelial monolayer function: cell-specific Gpld1-mediated secretion and functional role for GPI anchor. Am.J.Physiol Cell Physiol 291, C1258-C1270

42 Tsuzuki, S., Murai, N., Miyake, Y., Inouye, K., Hirayasu, H., Iwanaga, T., and Fushiki, T. (2005) Evidence for the occurrence of membrane-type serine protease 1/matriptase on the basolateral sides of enterocytes. Biochemical Journal 388, 679-687 


\section{Legends to figures}

Figure 1; HAI-1 can be expressed recombinantly in MDCK cells. Cell extracts of transfected (T) and non-transfected (NT) MDCK cells were analyzed by western blotting. Positions of marker proteins and their molecular masses in $\mathrm{kDa}$ are indicated. After stripping, the blots were reprobed with an antibody against the transferrin receptor (TR) as a loading control, indicating that equal amounts of cell extracts were applied to each lane.

Figure 2. HAI-1 is mainly located on the basolateral plasma membrane together with its cognate protease matriptase. MDCK cells expressing HAI-1 were labelled for HAI-1 in the absence of detergent to detect HAI-1 at the plasma membrane (HAI- $\left.1_{\text {surface}}\right)(a$ and d) thereafter labelling for HAI-1 was repeated using the same primary antibody but a different secondary antibody in the presence of detergent to detect both intracellular and extracellular HAI-1 (HAI- $\left.\mathrm{I}_{\text {total }}\right)(\mathrm{b}$ and e). Overlay of $a$ and $b$ are shown in $c$, and overlay of $d$ and e are shown in f. Tight filter grown MDCK cells were biotinylated from either the apical side $(\mathrm{g})$ or the basolateral side $(\mathrm{j})$ and thereafter labelled for HAI-1 ( $h$ and $k$ ). Overlay of $g$ and $h$ is shown in $i$ and overlay of $j$ and $k$ is shown in 1 . HAI-1 is mainly located on the basolateral membrane in the mouse mammary gland. Mouse mammary gland from mouse at $10^{\text {th }}$ day of lactation was labelled for HAI- 1 and analyzed by confocal microscopy $(\mathrm{m})$. MDCK cells expressing HAI-1 were transiently transfected with an expression vector coding for matriptase. Cells were labelled for HAI-1 (n) and matriptase (o). Overlay of $\mathrm{n}$ and $\mathrm{o}$ is shown in $\mathrm{p}$.

Figure 3. HAI-1 is exocytosed mainly to the basolateral membrane. Tight filter-grown monolayers of MDCK-21 cells were pulse-labelled with [35S]methionine for $10 \mathrm{~min}$ and chased for the times indicated. Plasma membrane proteins present in either the apical or basolateral membrane domains were biotinylated with s-NHS- biotin. Biotinylated HAI-1 was purified by immunoprecipitation, then released from the beads by boiling and thereafter precipitated with streptavidin-agarose. The resulting purified HAI-1 was analyzed on NuPAGE gels and quantified on a phosphorimager. The distribution of HAI-1 at the two membrane domains is expressed as a percentage of total HAI-1 at the time of maximal expression at the cell surface. The error bars represent the mean $+/-\mathrm{SD}(\mathrm{n}=3)$.

Figure 4. HAI-1 is proteolytically cleaved and released primarily from the basolateral membrane. Tight filter-grown monolayers of MDCK expressing HAI-1 were pulse-labelled with [35S]methionine for $10 \mathrm{~min}$ and chased for the times indicated. Media exposed to the apical side of the cells (A media), the basolateral side (B media) and cell extract were collected and immunoprecipitated. The resulting purified HAI-1 was analyzed on NuPAGE gels and quantified on a phosphorimager. A graphic presentation of the kinetics of HAI-1 proteolytic processing is presented in $b$ where the different fragments are depicted as percentage of total amount of HAI-1 at the time of maximal expression. The error bars represent the mean $+/-\operatorname{SD}(n=4)$.

Figure 5. HAI-1 is rapidly endocytosed. MDCK-21 cells were grown on plastic until subconfluence and biotinylated with the cell membrane impermeable s-NHS-SS-biotin. After biotinylation, proteins were allowed to internalize for the times indicated at either $4^{\circ} \mathrm{C}$ or $37^{\circ} \mathrm{C}$. Subsequently surface-exposed biotin was stripped by membrane impermeable reducing agent, glutathione $(+)$, or reduction was omitted (-) and the cells were extracted. The cell extracts were streptavidin precipitated and the precipitates were analyzed by immunoblotting using the HAI-1 antibody. With immediate stripping of biotin after biotinylation, only a minor background of non-reduced HAI-1 
could be detected. The bars represent the mean $+/-\mathrm{SD}(\mathrm{n}=4)$ except for non-reduced samples where only a single determination is shown.

Figure 6. Transcytosis of HAI-1 in MDCK cells. After a pulse-chase with [35S]methionine, MDCK cells expressing HAI-1 were biotinylated at the basolateral membrane and chased for 0 hours or 4 hours at $37^{\circ} \mathrm{C}$. After the chase cells were either not reduced $(\div)$ or reduced from the apical (A) side or the basolateral (B) side. Biotinylated HAI-1 was purified by immunoprecipitation followed by streptavidin precipitation and analyzed on NuPAGE gels. The bars represent the mean $+/-\mathrm{SD}$ $(n=3)$.

Figure 7. HAI-1 accumulates intracellularly upon bafilomycin treatment. Cell were immunostained for HAI-1 in the absence of detergent ( $a$ and $d$ ) and then in the presence of detergent ( $b$ and e) after bafilomycin treatment ( $\mathrm{d}$, e and $\mathrm{f}$ ). Controls were treated with DMSO (a, b and c). HAI-1 not only clearly locates to the basolateral membrane (a and d) but obviously also accumulates intracellularly upon bafilomycin treatment (e). The overlay of the control and bafilomycin treated cells are shown in $\mathrm{c}$ and $\mathrm{f}$, respectively.

Figure 8. The intracellular transport of HAI-1 in MDCK cells. HAI-1 is from the Golgi apparatus transported mainly to the basolateral plasma membrane (A) but we can not rule out that a minor fraction is transported directly to the apical plasma membrane (B). HAI-1 is endocytosed from the basolateral plasma membrane $(\mathrm{C})$ and at least partly recycled back to the basolateral plasma membrane (D). A substantial fraction of the HAI-1 molecules at the basolateral plasma membrane is transcytosed to the apical plasma membrane (E). From both the apical and the basolateral plasma membrane there is a partial proteolytic release of the HAI-1 ectodomain symbolized by a pair of scissors. A fraction of the HAI-1 molecules is eventually degraded in the lysosomes. It was not determined from which cellular compartment HAI-1 is directed to the lysosomes, but it is most likely derived from the apical plasma membrane (F), as this would account for the low steady state concentration of HAI-1 found in this compartment. 


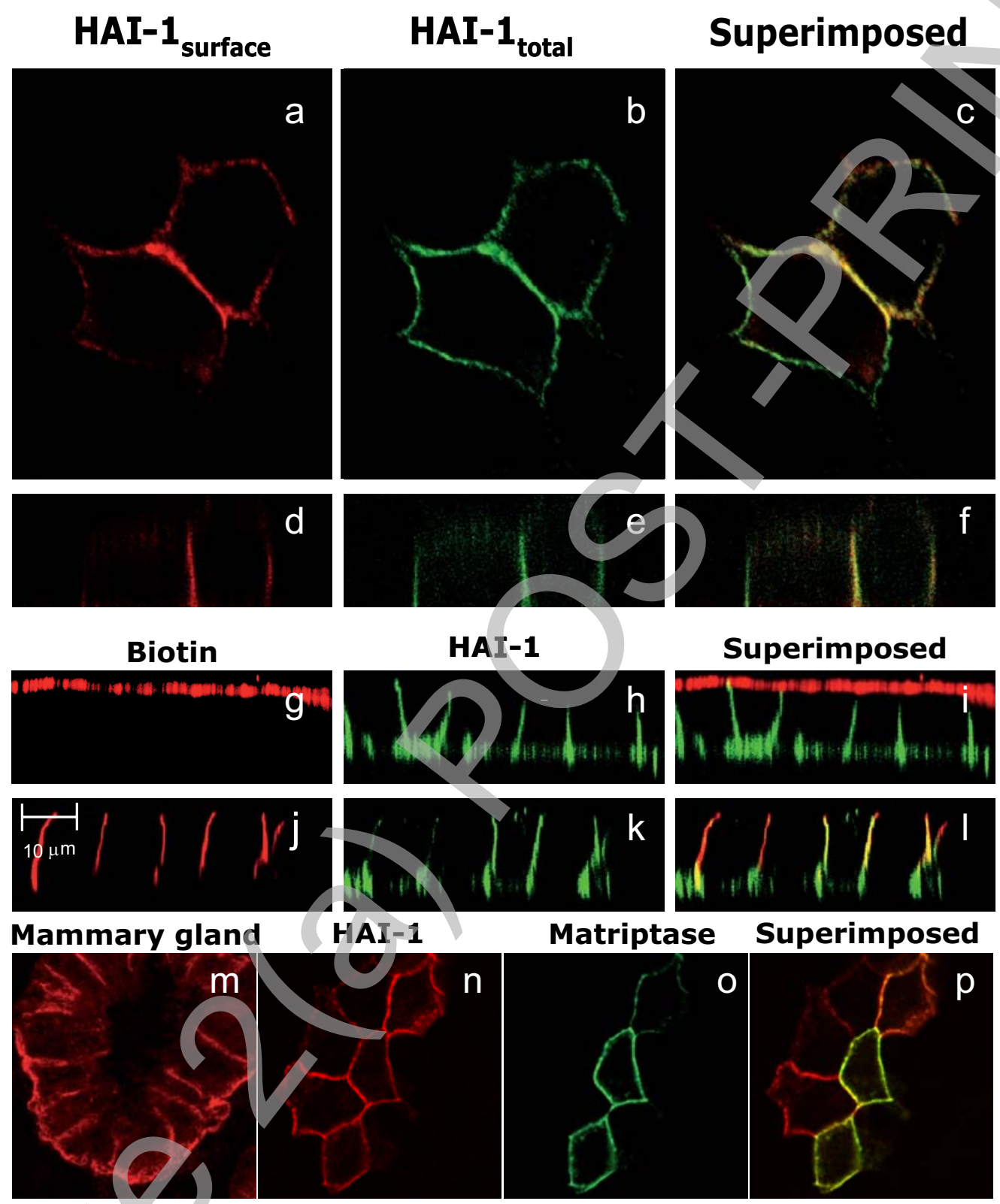


A

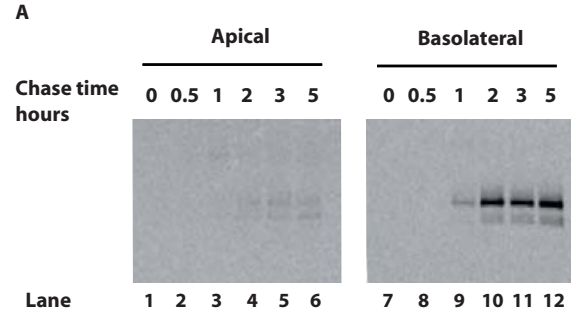

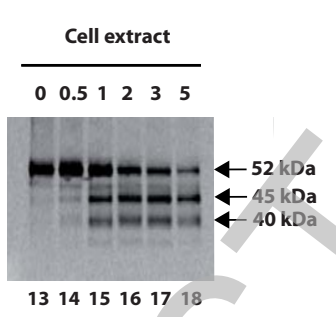

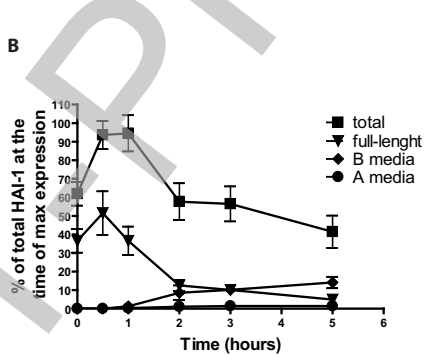

Licenced copy. Copying is not permitted, except with prior permission and as allowed by law. (c) 2008 The Authors Journal compilation (c) 2008 Biochemical Society 
Chase time $(\min ) \quad 0 \quad 0 \quad 5 \quad 5 \quad 10 \quad 10 \quad 15 \quad 15$

Chase temp (C) $\quad 4 \quad 4 \quad \begin{array}{lllllll}37 & 37 & 37 & 37 & 37 & 37\end{array}$

Reduction
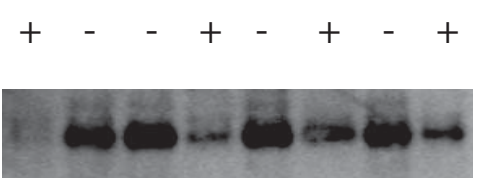

Endocytosis

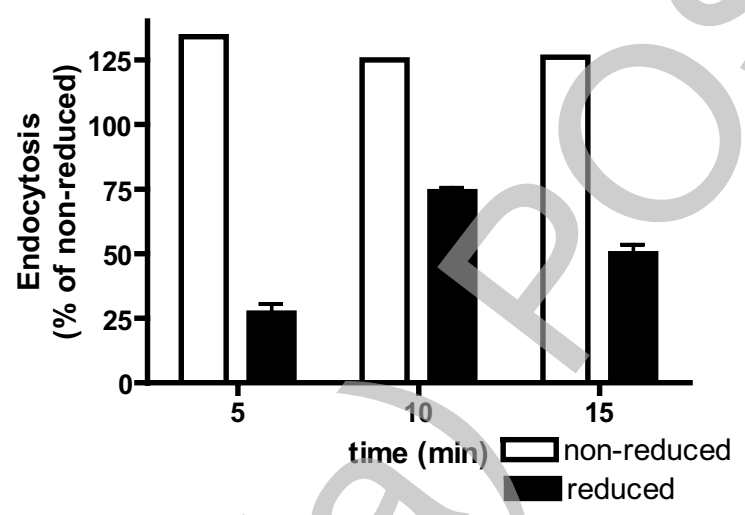




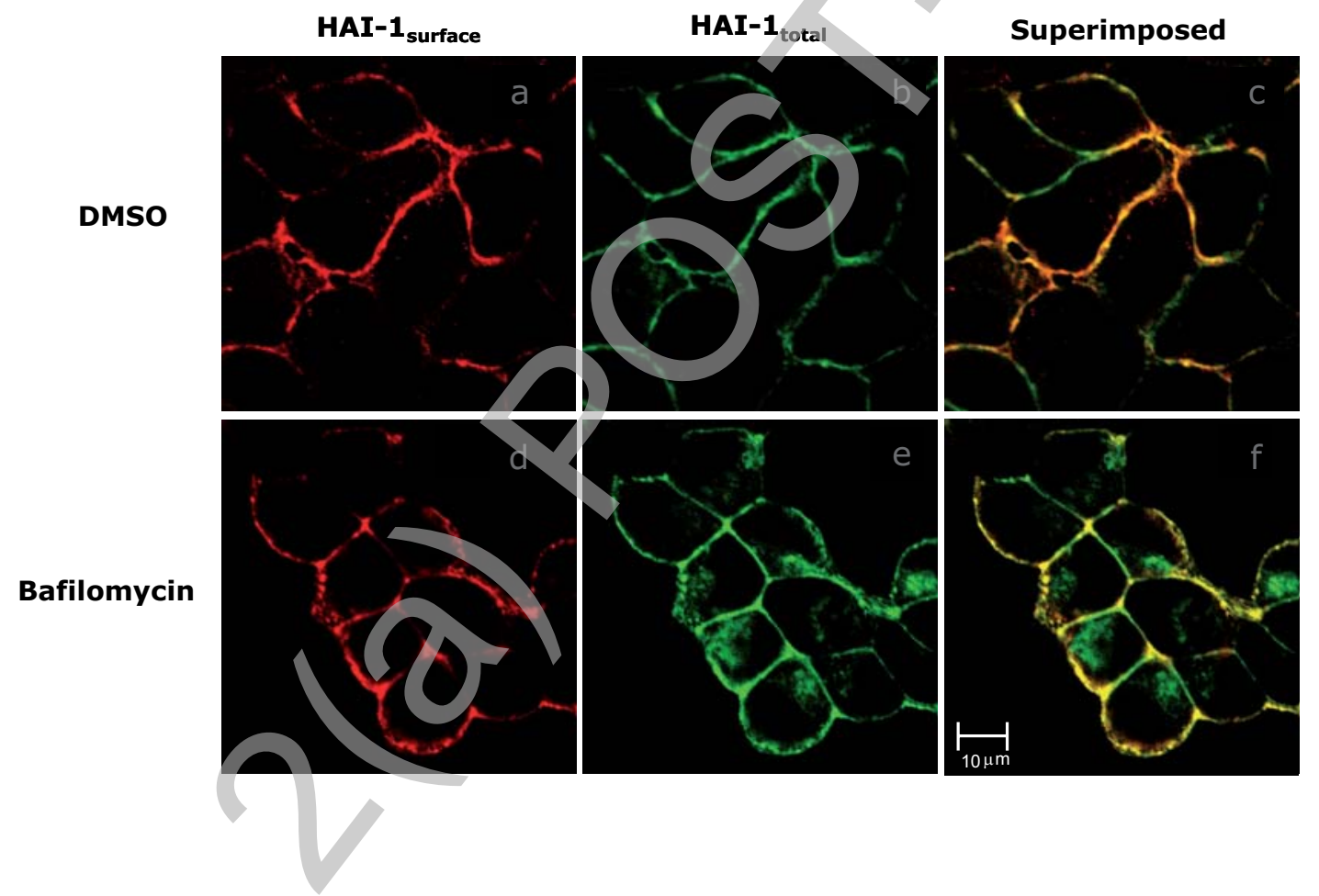


